\title{
Identifying dormancy class and storage behaviour of champak (Magnolia champaca) seeds, an important tropical timber tree
}

\author{
M. Thilina R. Fernando ${ }^{1 *}$, K.M.G. Gehan Jayasuriya ${ }^{2}$, Jeffrey L. Walck ${ }^{1}$, A.S.T.B. Wijetunga ${ }^{2}$ \\ ${ }^{I}$ Department of Biology, Middle Tennessee State University, Murfreesboro, TN 37132, USA. \\ ${ }^{2}$ Department of Botany, Faculty of Science, University of Peradeniya, Peradeniya.
}

\begin{abstract}
Magnolia champaca is a culturally important tree in the tropics with a high commercial value. Its natural regeneration is rare. Hence, the species is usually propagated from seeds but with great difficulties. The class of dormancy in $M$. champaca seeds has been reported to be physical, physiological, and morphological. Their storage behaviour as orthodox, intermediate, and recalcitrant has been reported by various authors. During the present research, seeds of this species in Sri Lanka were collected to determine their dormancy class and storage behaviour. Both scarified and non-scarified seeds imbibed water; however, high germination occurred only on gibberellic acid $\left(\mathrm{GA}_{3}\right)$ showing the presence of physiological dormancy. Embryos elongated inside of seeds at warm temperatures before radicle emergence indicating morphological dormancy. Thus, seeds have morphophysiological dormancy (MPD) and probably the nondeep simple level. The moisture content of fresh mature seeds was $25 \%$. Low germination occurred on $\mathrm{GA}_{3}$ for seeds dried to $10 \%$ moisture content, and the seeds stored dry at 4 and $-1{ }^{\circ} \mathrm{C}$ for 1 month did not germinate. Thus, the storage behaviour may be best classified as intermediate. Knowing that the seeds of this species have MPD allows future studies to partition the factors driving embryo growth, unblocking physiological dormancy, and stimulating germination in nature and in propagation. But the storage behaviour may limit seed usage in propagation programmes relying on stored seeds.
\end{abstract}

Keywords: Embryo growth, intermediate storage, Magnolia champaca, Michelia champaca, moisture content, morphophysiological dormancy.

\section{INTRODUCTION}

Magnolia champaca (L.) Baill. ex Pierre (= Michelia champaca L.), commonly known as champak, grows naturally in primary lowlands to montane rainforests of the Eastern sub-Himalayan region as well as the Western Ghats (Troup, 1921; Hossain \& Nizam, 2002). It is extensively planted in other parts of tropical Asia (Sri Lanka to Indonesia, Vietnam and China) and cultivated in tropical Central and South America and Africa (Candiani et al., 2004; Orwa et al., 2009; Tropicos $\AA$, 2012). Magnolia champaca is well known for its sweetly scented flowers (Armiyanti et al., 2010), and various parts of the plant provide fodder, timber, fuel, medicines, and antifungal compounds (Orwa et al., 2009). The species is often planted around Hindu and Jain temples. In addition, the plant has been identified as a well performing primary tree species in reforestation and restoration projects throughout South and South Eastern Asia (Hoque et al., 2004; Raman et al., 2009; Bhatt et al., 2010).

The natural regeneration of the species is rare, and hence, it is often grown in nurseries from seeds with great difficulty before out-planting (Bahuguna et al., 1987; Armiyanti, 2010). Four to twelve $M$. champaca seeds are enclosed in a follicle, which naturally split open at maturity (Norman, 1971). Propagation from seeds is complicated due to numerous factors (Norman, 1971; Campbell, 1980; Bahuguna et al., 1988; Beniwal \& Singh, 1989; Beniwal \& Lal, 1993; Lal et al., 1997; Murali, 1997; Bisht \& Ahlawat, 1999; Hossain \& Nizam, 2002; Candiani et al., 2004): highly variable viability, 'hard' seed/fruit coat, very low $(2-3 \%)$ to low $(23-39 \%)$ germination, and slow germination (1 week to 4 months). However, moderate $(50-53 \%)$ to high $(68-86 \%)$ germination in seeds has also been reported (Norman, 1971; Campbell, 1980; Bahuguna et al., 1987; Robbins, 1988; Lal et al., 1997; Bisht \& Ahlawat, 1999).

\footnotetext{
*Corresponding author (mrf3c@mtmail.mtsu.edu)
} 
Various treatments have been tried to enhance the germination. The 'hard' seed/fruit coat has been suggested to be responsible for delayed germination implying the presence of physical dormancy. However, seed coat softening treatments (even complete removal of the seed coat) have failed to improve germination (Bahuguna et al., 1988), and in some instances mechanical scarification decreased germination (Norman, 1971). Bahuguna et al. (1988) classified seeds as having physiological dormancy based upon enhanced germination (up to $80 \%$ ) with gibberellic acid $\left(\mathrm{GA}_{3}\right)$. In contrast, Baskin and Baskin (1998) classified seeds of the species as morphologically dormant based on: (1) the species being in Magnoliaceae, which is known to have underdeveloped embryos that must grow inside the seed before the radicle emerges and (2) germination (albeit low percentage) occurring without any treatments indicating no physiological component to dormancy (Beniwal \& Singh, 1989). Supporting this latter contention is the fact that simply removing the aril enhances germination from $0-4 \%$ to $74-86 \%$ (Robbins, 1988; Candiani et al., 2004).

Seeds of $M$. champaca are also short-lived (about 2-3 weeks), but the loss of viability can be minimized by moist storage especially at low temperatures $\left(5^{\circ} \mathrm{C}\right)$ for up to 9 months (Troup, 1921; Campbell, 1980; Bahuguna et al., 1987; Beniwal \& Singh, 1989; Murali, 1997; Bisht $\&$ Ahlawat, 1999). The species has been reported to be recalcitrant or 'short-lived orthodox' due to its relatively short life span and the requirement of high moisture to maintain viability (Bahuguna et al., 1987; Robbins, 1988; Bisht \& Ahlawat, 1999). In a graph of seed weight vs seed moisture content, $M$. champaca was plotted between the orthodox and recalcitrant species but closer to orthodox (Hong \& Ellis, 1996). The moisture content in fresh seeds varies from $9 \%$ (Candiani et al., 2004) to $21 \%$ (Bahuguna et al., 1987) to $30 \%$ (SID, 2008) and the seeds can tolerate desiccation up to $11 \%$ (Robbins, 1988). Although these values fall mostly within the range of orthodox species (Hong \& Ellis, 1996), SID (2008) suggested that further investigations with low moisture contents and with sub-zero temperatures are needed to better understand the storage behaviour.

The main purpose of the present study was to determine the class of dormancy (Baskin \& Baskin, 2004) in $M$. champaca seeds. Imbibition tests, germination tests under laboratory conditions and with $\mathrm{GA}_{3}$, and embryo growth studies were used to examine nondormancy and physical, physiological, combinational (physical + physiological), morphological, and morphophysiological (morphological + physiological) dormancies. The study was also aimed at better understanding of the storage behaviour of $M$. champaca seeds by investigating (1) the moisture content of fresh seeds and (2) the viability of dried seeds and of the seeds under various storage conditions.

\section{METHODS AND MATERIALS}

\section{General procedures}

Seeds were collected from (freshly) fallen dehisced fruits of $M$. champaca trees along roadsides at the University of Peradeniya, the Royal Botanic Gardens in Peradeniya and a home garden in Matale, Sri Lanka, during the late fruiting season from July to September 2010. They were placed in polythene bags and taken to the laboratory where the aril surrounding the seeds was removed manually and the seeds were washed with water. Studies were carried out within 1 wk of collection of the seeds at $27^{\circ} \mathrm{C}$ with fluorescent ceiling lights and diffuse sunlight from windows for ca. $10 \mathrm{~h}$ per day. Seeds were placed on Whatman No. 1 filter papers moistened either with water or 500 ppm $\mathrm{GA}_{3}$ in $9 \mathrm{~cm}$ diameter plastic petri dishes during the experiments.

\section{Imbibition test}

Fifteen seeds were manually scarified by removing a small portion of the seed coat using a razor blade and the initial weight of each seed was measured; 15 nonscarified seeds also were weighed. Seeds of both sets were placed on moist filter papers in petri dishes and kept in the laboratory. Each seed was re-weighed after $3,5,7,24$ and $48 \mathrm{~h}$. The percentage change in mass was calculated.

\section{Seed germination}

Two experiments were conducted to examine the germination (i.e. appearance of the radicle). In the first experiment, germination was tested under four conditions: (1) non-scarified and moistened with water, (2) manually scarified (see above for method) and moistened with water, (3) non-scarified and moistened with $\mathrm{GA}_{3}$, and (4) scarified and moistened with $\mathrm{GA}_{3}$. Each treatment was conducted with three samples, each having 15 seeds, and on filter papers in petri dishes. Seeds were kept moist with water or $\mathrm{GA}_{3}$ in the laboratory and checked for germination at $2 \mathrm{~d}$ intervals for 3 months. For the second experiment, three sets of 15 seeds each were kept moist with water on filter papers in petri dishes in the laboratory. Seeds in the first, second, and third set were transferred to filter papers moistened with $\mathrm{GA}_{3}$ after 15,30 , and 50 days, respectively. Seed germination was recorded throughout the experimental period (before and after being transferred to $\mathrm{GA}_{3}$ ) at $5 \mathrm{~d}$ intervals for 105 days. 


\section{Embryo and seed length measurements}

A set of seeds was placed on a filter paper moistened either with water or with $\mathrm{GA}_{3}$ in a petri dish and kept in the laboratory. Embryos were removed from seeds with a scalpel, and the length of the embryos and the seeds were measured using a compound microscope with a micrometer. The length of embryos and seeds were recorded at $2-9 \mathrm{~d}$ intervals starting on day 2 for seeds on water and on day 4 for seeds on $\mathrm{GA}_{3}$. Measurements were taken over a $75 \mathrm{~d}$ period or until all the seeds had rotted (on $\mathrm{GA}_{3}$ ). Five seeds in each treatment were used at each measurement, with the exception of three seeds on $\mathrm{GA}_{3}$ in the last two measurements. To determine the critical length at which the embryo maximally grows inside the seed before radicle emergence, a set of seeds was treated with $\mathrm{GA}_{3}$, and the embryo and seed lengths were determined for germinated seeds. For seeds that had germinated, the length of the embryos were measured up to the point where the radicle exited from the seed. From the measurements, the ratio of embryo length to seed length was calculated.

\section{Moisture content}

The initial weight of the six samples, each with six fresh seeds, was measured. The samples were oven dried for $3 \mathrm{~h}$ at $120{ }^{\circ} \mathrm{C}$ and the final weight of each sample was measured (ISTA, 2008). Another six samples, each with six seeds, were kept on dry filter papers in petri dishes in the laboratory, which had the same relative humidity and temperature as outside, for 30 days in order to observe the moisture content changes under simulated natural conditions. The samples were then oven dried (as before) and the final weight of each sample was measured. Moisture content for both sets of samples was calculated based on initial mass.

\section{Viability and storage}

Two experiments were set-up to examine the viability under various storage conditions. The first experiment included three samples, each with 15 seeds that were dried up to $10 \%$ moisture content (fresh mass basis) in the laboratory. For the second experiment, two samples with three replicates containing six seeds each were wrapped with aluminium foil and then placed in petri dishes that were sealed in polythene bags. One sample was kept dry and stored for 1 month in a refrigerator at $4{ }^{\circ} \mathrm{C}$ while the other sample was stored at $-1^{\circ} \mathrm{C}$. Following the specified condition in each experiment, seeds were placed on filter papers moistened with $\mathrm{GA}_{3}$ and tested for viability (via germination test) with scoring done at $2 \mathrm{~d}$ intervals for 50 days.

\section{Statistical analysis}

Means were compared using $t$-test or one-way analysis of variance (ANOVA) followed by protected least significant difference tests (PLSDs, $\mathrm{p}=0.05$ ) (SPSS, 2010). Germination percentages were calculated based on the number of seeds placed in a petri dish, and they were arcsine square-root transformed for statistical analysis.

\section{RESULTS}

\section{Imbibition test}

Both scarified and non-scarified seeds absorbed water (Figure 1), and the differences at 48 hours were not significant $(t$-test, $\mathrm{p}=0.163)$. Increase in the mass of seeds from both treatments was $14-16 \%$ at 48 hours.

\section{Seed germination}

In the first experiment, germination of both scarified and non-scarified seeds was significantly higher (1-way ANOVA, $\mathrm{p}<0.0001$ ) on $\mathrm{GA}_{3}$ than on water (Figure 2 ). No additional germination occurred after day 23. Nongerminated seeds on $\mathrm{GA}_{3}$ eventually rotted but the seeds that were kept on water for up to 3 months never germinated or rotted. For the second experiment, $0-20 \%$ of the seeds in sets 1, 2, and 3 germinated prior to $\mathrm{GA}_{3}$ addition on day 15,30 , and 50 , respectively (Figure 3). Germination increased to $67-80 \%$ among the sets following $\mathrm{GA}_{3}$ treatment.

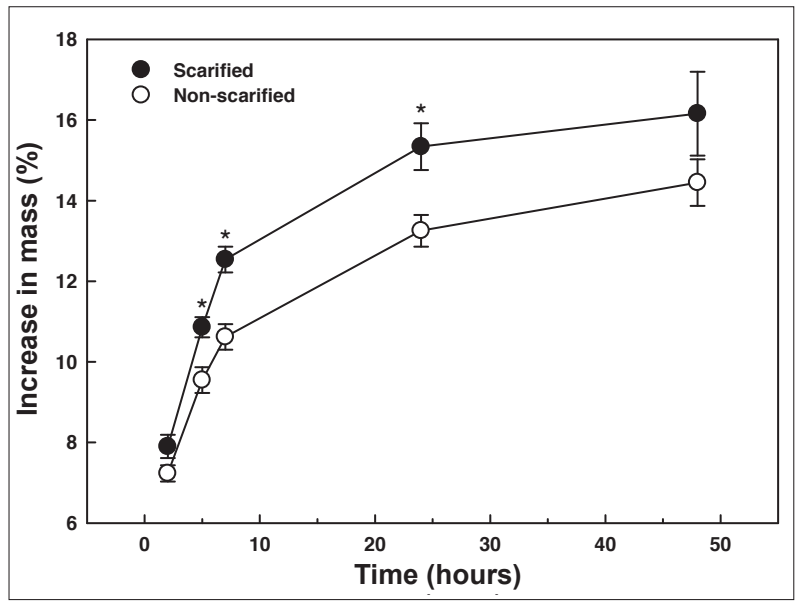

Figure 1: Imbibition of manually scarified and of non-scarified seeds of Magnolia champaca. Error bars are $\pm 1 \mathrm{SE}$. An asterisk indicates the significant difference between scarified and non-scarified conditions ( $t$-test, $\mathrm{p} \leq 0.05)$. 


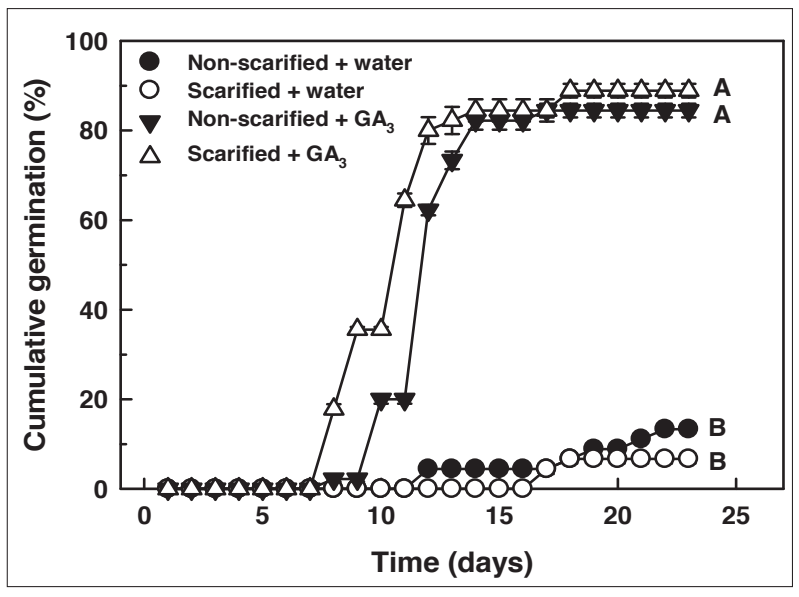

Figure 2: Mean ( $\pm \mathrm{SE}$ ) germination of manually scarified and nonscarified seeds of Magnolia champaca on gibberellic acid $\left(\mathrm{GA}_{3}\right)$ or water under laboratory conditions. Means at day 23 with dissimilar letters are significantly different (PLSD, $\mathrm{p}=0.05)$.

\section{Embryo length and seed length measurements}

Seeds on $\mathrm{GA}_{3}$ had a significantly higher $(\mathrm{p}=0.016)$ embryo : seed length ratio $(0.461)$ at day 23 , than those on water (0.211) at day 21 (Figure 4). No additional measurements were made on $\mathrm{GA}_{3}$ treated seeds after day 23 since they were all rotted. For seeds on water, the ratio remained low from day 21 until the end of the experiment on day 75. However, seeds on water were judged to be viable since their embryos were white and firm (as opposed to brown and soft). The mean $( \pm \mathrm{SE})$ ratio in the germinated seeds was $0.608 \pm 0.028$.

\section{Moisture content and viability}

The mean $( \pm \mathrm{SE})$ moisture content of fresh seeds was 25.2 $\pm 1.6 \%$ and it was significantly reduced during 30 days of storage in the laboratory $(5.7 \pm 0.9 \%)(p<0.0001)$. In the first experiment, a mean $( \pm \mathrm{SE})$ germination of 24 $\pm 0 \%$ occurred within 14 days after the $\mathrm{GA}_{3}$ treatment for seeds dried to $10 \%$ moisture content; no additional germination took place after 14 days and all the nongerminating seeds eventually rotted. For dry seeds placed at 4 and $-1{ }^{\circ} \mathrm{C}$ in the second experiment, none germinated and were ultimately rotted.

\section{DISCUSSION AND CONCLUSION}

Seeds of $M$. champaca remained viable and a few seeds germinated on water at laboratory temperatures over 3 months (Figure 2) or ca. 1.5 months (Figure 3).
Baskin and Baskin (2004) recommended that the seeds be considered dormant if the seeds are placed under appropriate conditions and they do not germinate (or low percentages do so) within about 1 month. Since most $M$. champaca seeds did not germinate without treatment, it was concluded that many of the seeds in the present study as well as in other studies that reported low germination (Bahuguna et al., 1988; Beniwal \& Singh, 1989; Beniwal \& Lal, 1993; Murali, 1997; Candiani et al., 2004) were dormant at maturity. Although some studies have reported moderate to high germination (Norman, 1971; Campbell, 1980; Bahuguna et al., 1987; Robbins, 1988; Lal et al., 1997; Bisht \& Ahlawat, 1999), the possible influence of pre-sowing storage conditions or the length is uncertain. We cannot rule out the possibility that seeds in some populations may have only a slight degree of dormancy.

Physically dormant seeds are characterized by a water impermeable seed and/or fruit coat, and thus, can imbibe water only if specialized structures on the seed is opened or if the seed is damaged allowing water uptake (Baskin \& Baskin, 1998). Although M. champaca seeds are described as very hard and impermeable to water (Norman, 1971; Bahuguna et al., 1988; SID, 2008), both scarified and non-scarified seeds imbibed water (Figure 1) and germinated in the presence of high percentages on $\mathrm{GA}_{3}$ (Figure 2). Thus, seeds of this species are neither physically dormant nor conditionally (physical + physiological) dormant.

Embryos inside of $M$. champaca seeds elongated about $190 \%$ (from ca. 0.21 to $0.61 \mathrm{~mm}$ ) before radicle emergence. This aspect showed that the seeds have a morphological component to their dormancy. Due to embryo growth, an immediate radicle emergence would not be expected from the seeds and the radicles did not begin to emerge from the seeds for 8 days (or longer) after the start of $\mathrm{GA}_{3}$ treatment (Figures $2-4$ ). In addition to embryo growth, seeds treated with $\mathrm{GA}_{3}$ germinated at high percentages but those not treated germinated at low percentages (Figure 2). Moreover, seeds that remained moist for up to 50 days did not germinate at high percentages unless they were treated with $\mathrm{GA}_{3}$ (Figure 3 ). Our results support the conclusion of Bahuguna et al. (1988) that $M$. champaca seeds have a physiological component to dormancy. Seeds like $M$. champaca, that have both a morphological component (embryo growth) as well as a physiological block are defined as having morphophysiological dormancy (MPD).

The levels of MPD are first divided into two categories based on temperatures at the time of embryo growth: warm temperatures $\left(\geq 15^{\circ} \mathrm{C}\right)$ are needed for embryo growth in 


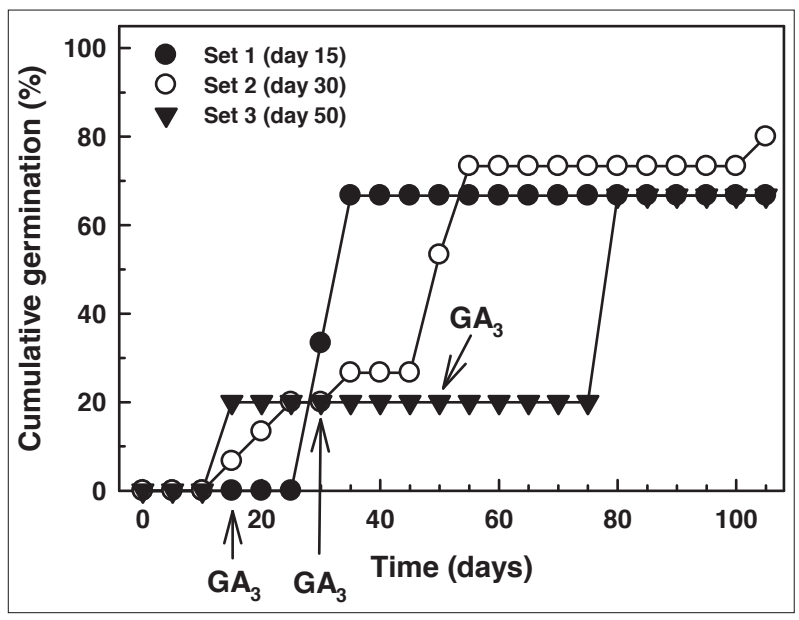

Figure 3: Germination for three sets of Magnolia champaca seeds on filter paper moistened with water under laboratory conditions $\left(27^{\circ} \mathrm{C}\right.$ with light during day) and then transferred to $\mathrm{GA}_{3}$ on day 15,30 , and 50 , respectively.

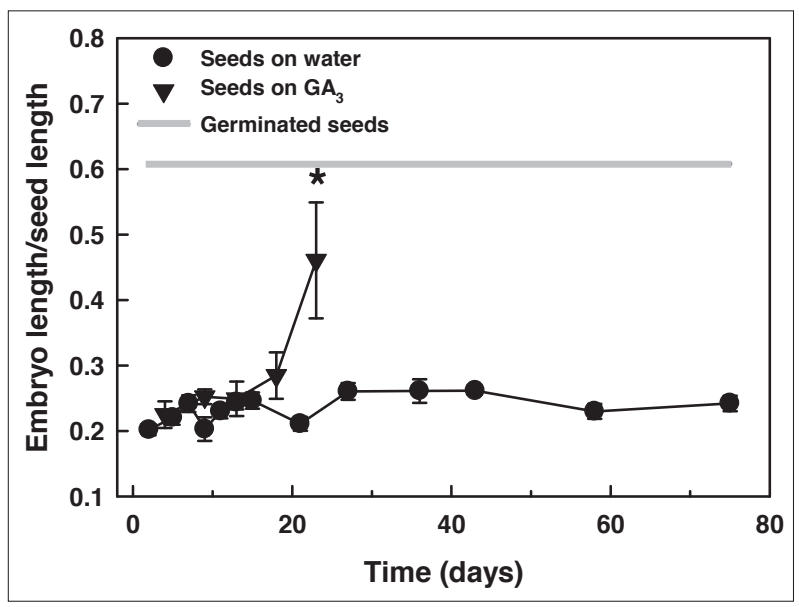

Figure 4: Mean ( \pm SE) embryo length:seed length ratio for Magnolia champaca seeds on $\mathrm{GA}_{3}$ or water under laboratory conditions. The ratio in germinated seeds was 0.608 (grey line). An asterisk indicates significant difference between treatments $(t$-test, $\mathrm{p} \leq 0.05)$.

seeds with simple levels of MPD and cold temperatures $\left(0-10^{\circ} \mathrm{C}\right)$ for those with complex levels of MPD (Baskin \& Baskin, 2004). Considering that (1) embryos in $\mathrm{GA}_{3}-$ treated seeds grew in the laboratory at $27^{\circ} \mathrm{C}$ (Figure 4), (2) M. champaca grows primarily in (lowland) tropical regions where temperatures average $>20{ }^{\circ} \mathrm{C}$ (Smith \& Smith, 2009), and (3) cold stratification at $5{ }^{\circ} \mathrm{C}$ did not overcome dormancy (Bahuguna et al., 1988), it was concluded that the seeds have a simple type of MPD.
Simple MPD is divided into several categories depending on the requirements to break dormancy and whether $\mathrm{GA}_{3}$ could overcome it. Intermediate and deep levels of simple MPD require warm followed by cold stratification (warm + cold) to break dormancy, but non-deep simple MPD needs only warm or cold stratification (Baskin \& Baskin, 2004). GA 3 overcomes dormancy in seeds with non-deep and intermediate simple MPD; it substitutes for warm but not cold stratification in seeds with deep simple MPD. The level of MPD in seeds of $M$. champaca apparently is non-deep simple, since (1) cold stratification did not alleviate dormancy (Bahuguna et al., 1988) and (2) $\mathrm{GA}_{3}$ effectively broke it (Figures $2-4$ ).

The moisture content of fresh $M$. champaca seeds in this study $(25 \%)$ was within the range $(9-30 \%)$ reported in other studies (Bahuguna et al., 1987; Candiani et al., 2004; SID, 2008). Orthodox, intermediate, and recalcitrant seeds generally have $<20-50,23-55$, and $36-90 \%$, moisture contents at maturity, respectively (Hong \& Ellis, 1996). No generalization is possible when the moisture content is between 25 and $55 \%$, but if it is $<35 \%$ then the species is unlikely to show recalcitrant behaviour. Only some of the seeds remained viable and germinated when dried to $10 \%$ moisture content, confirming the findings reported by Robbins (1988) where the seeds were dried to $11 \%$ moisture content. The seeds also remained viable for up to 2.5 months at warm temperatures if kept moist (Figure 4). However, the seeds died when stored dry at temperatures reduced to $-1{ }^{\circ} \mathrm{C}$ for 1 month. Seeds that can survive drying to $10-12 \%$ moisture content but die when dried to $5 \%$ or when stored hermetically at $-20^{\circ} \mathrm{C}$ for 3 months are classified as intermediate (Hong \& Ellis, 1996). Although the storage was not hermetic or subfreezing, the data suggest that seeds in the present study would not have survived in these conditions. Based on the moisture content in fresh seeds as well as the storage behaviour, the seeds of M. champaca would be best classified as intermediate.

The next step for understanding the dormancy and germination in $M$. champaca seeds is to resolve the temperature and moisture regimes under which morphological and physiological dormancy break occurs in nature and in out-of-door propagation. Knowing that seeds of this species have MPD allows ecologists and nurseries to study the partitioning of environmental factors driving embryo growth, unblocking physiological dormancy, and stimulating germination. Delays in emergence following sowing are expected due to MPD, and this aspect may limit the possibility of $M$. champaca seeds being ready-on-demand. Nurseries may need to consider the possibility of treating seeds with $\mathrm{GA}_{3}$ before 
sowing to achieve high emergence. In addition, the storage behaviour of $M$. champaca seeds may restrict its use in propagation and land rehabilitation programmes that rely on stored seeds.

\section{REFERENCES}

1. Armiyanti Kadir M.A., Kadzimin S. \& Panjaitan S.B. (2010). Plant regeneration of Michelia champaca L., through somatic embryogenesis. African Journal of Biotechnology 9: 2640 - 2647.

2. Bahuguna V.K., Rawat M.M.S. \& Naithani K.C. (1987). Investigation on the seed of Michelia champaca Linn. for perfection of optimum conditions of storage. Indian Forester 113: 243 - 248.

3. Bahuguna V.K., Rawat M.M.S. \& Naithani K.C. (1988). Study on dormancy and treatment to enhance germination of champ (Michelia champaca, Linn.) seed. Indian Forester 114: $317-319$.

4. Baskin C.C. \& Baskin J.M. (1998). Seeds: Ecology, Biogeography, and Evolution of Dormancy and Germination. Academic Press, San Diego, USA.

5. Baskin J.M. \& Baskin C.C. (2004). A classification system for seed dormancy. Seed Science Research 14: 1 - 16.

6. Beniwal B.S. \& Lal P. (1993). Study of effective insecticide/ fungicide to protect seed of Michelia champaca Linn. for getting higher germination in the nursery. Indian Forester 119: $151-153$.

7. Beniwal B.S. \& Singh N.B. (1989). Observations of the flowering, fruiting and germination behaviour of some useful forest plants of Arunachal Pradesh. Indian Forester 115: $216-227$.

8. Bhatt B.P., Singha L.B., Satapathy K.K., Sharma Y.P. \& Bujarbaruah K.M. (2010). Rehabilitation of shifting cultivation areas through agroforestry: a case study in Eastern Himalaya, India. Journal of Tropical Forest Science 22: $13-20$.

9. Bisht N.S. \& Ahlawat S.P. (1999). Seed Technology. SFRI Information Bulletin No. 7. State Forest Research Institute, Itanagar, India.

10. Campbell M.W. (1980). Plant propagation for reforestation in Nepal. Technical Note 1/80. Nepal-Australia Forestry Project, Department of Forestry, Australian National Univercity for the Australian Development Assistance Bureau, Department of Foreign Affairs, Canberra Publishing and Printing Co., Canberra, Australia.

11. Candiani G., Galetti M. \& Cardoso V.J.M. (2004). Seed germination and removal of Michelia champaca L.
(Magnoliaceae) in eucalypt stands: the influence of the aril. Revista Árvore 28: 327 - 332.

12. Hong T.D. \& Ellis R.H. (1996). A protocol to determine seed storage behaviour. IPGRI Technical Bulletin No. 1 (eds. J.M.M. Engels \& J. Toll), International Plant Genetic Resources Institute, Rome, Italy.

13. Hoque A.T.M.R., Hossain M.K., Mohiuddin M. \& Hoque M.M. (2004). Effect of inorganic fertilizers on the initial growth performance of Michelia champaca Linn. seedlings in the nursery. Journal of Biological Sciences 4: 489 497.

14. Hossain M.K. \& Nizam M.Z.U. (2002). Michelia champaca L. Tropical Tree Seed Manual (ed. J.A. Vozzo), pp. $572-574$. United States Department of Agriculture Forest Service, Washington DC, USA.

15. Lal P., Bisht N.S. \& Aggarwal S.K. (1997). Determination of proper depth of seed sowing in Michelia champaca in nursery. Indian Forester 123: 118 - 122.

16. Murali K.S. (1997). Pattern of seed size, germination and seed viability of tropical tree species in Southern India. Biotropica 29: 217 - 279.

17. Norman J.C. (1971). Germination of Michelia champaca seeds after various short storage and seed coat treatments. Proceedings of the International Seed Testing Association 36: $335-342$.

18. Orwa C., Mutua A., Kindt R., Jamnadass R. \& Simons A. (2009). Agroforestree database: a tree reference and selection guide, ver. 4.0. Available at http://www. worldagroforestry.org/resources/databases/agroforestree, Accessed 31 January 2012.

19. Raman T.R.S., Mudappa D. \& Kapoor V. (2009). Restoring rainforest fragments: survival of mixed-native species seedlings under contrasting site conditions in the Western Ghats, India. Restoration Ecology 17: 137 - 147.

20. Robbins A.M.J. (1988). Storage of champ (Michelia champaca) seed. Banko Janakari 2: 55 - 57.

21. SID (2008). Seed information database, ver. 7.1. Royal Botanic Gardens, Kew, UK. Available at http://data.kew. org/sid/, Accessed 6 February 2012.

22. Smith T.M. \& Smith R.L. (2009). Elements of Ecology, $7^{\text {th }}$ edition. Benjamin Cummings, San Francisco, USA.

23. SPSS. 2010. Version 19.0 for Windows. SPSS, Chicago.

24. Tropicos ${ }^{\circledR}$. (2012). Missouri Botanical Garden, St. Louis. Available at $h t t p: / / w w w . t r o p i c o s . o r g$, Accessed 31 January 2012.

25. Troup R.S. (1921). The Silviculture of Indian Trees, volume. 1. Dilleniaceae to Leguminosae (Papilionaceae). Clarendon Press, Oxford, UK. 